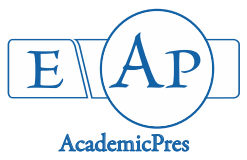

Joshi SK and Bala M (2020)

Notulae Scientia Biologicae 12(1):30-41

DOI: $10.15835 / \mathrm{nsb} 12110543$

Research Article

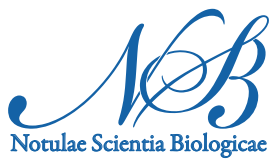

\title{
Phenological attributes of Pyracanth a crenulata - a high-value multipurpose shrub of the Himalaya
}

\author{
Soumai K. JOSHI ${ }^{1 *}$, Madhu BALA ${ }^{2}$ \\ ${ }^{1}$ Defence Institute of Bio-Energy Research, Defence R\&D Organisation, Field Station, 262501 Pithoragarh (Uttarakhand), \\ India; skantjoshi@gmail.com (*correspondingauthor) \\ ${ }^{2}$ Defence Institute of Bio-Energy Research, Defence R\&D Organisation, P.O. Arjunpur, 263139 Haldwani (Uttarakhand), \\ India;bala44@gmail.com
}

\begin{abstract}
Pyracantha crenulata is a high value multipurpose shrub of the Himalaya. Fruits of the species possess several therapeutic and nutraceutical properties and are edible. Undertaking phenological studies on highvalue wild plant species, particularly the ones that are yet to be domesticated, is particularly important as they provide baseline data on patterns of their vegetative growth, flowering, fruiting, fruit maturity, seed set etc. Considering these facts, the present study was carried out with the aim to identify and document the phenological features of $P$. crenulata and to study patterns of its phenological events under two habitat conditions. The study was carried out at two closely located sites, different in microsite conditions, at Pithoragarh (Uttarakhand), India, under the Western Himalaya in the Indian Himalayan Region (IHR) for two consecutive years. Five phenological events (emergence of new leaves and twigs; flowering; fruit setting and development; fruit drop and leaf fall) were recorded at fortnightly intervals, i.e., first fortnight and second fortnight in each month on selected individuals of the species, in both the sites. All the phenological phases investigated followed identical or near identical patterns across both sites so that there were no significant differences $(\mathrm{P}<0.05)$ between the sites in terms of phenological events and growth parameters recorded. Being an economically and ecologically valuable species, findings on the patterns of flowering and fruiting of P. crenulata are significant not only for management of its natural populations in the region, but will also serve as a baseline data for studies to be carried out for its domestication in future.

Keywords: fruit maturity; Himalayan firethorn; medicinal plants; Western Himalaya; wild edible plants

\section{Introduction}

Pyracantha crenulata (D. Don) M. Roemer (Rosaceae), commonly called as Himalayan firethorn, is an evergreen thorny shrub species that grows between 1,000 and 2,400 $\mathrm{m}$ above mean sea level (a.m.s.l.), from Himalaya to South-West China and Myanmar. The species grows up to a height of two meter and occurs on shrubberies, open slopes and near cultivated areas. P. crenulata is used in multiple ways in the Himalayan region. Its ripen fruits are eaten directly by the local communities in Uttarakhand, where it is commonly
\end{abstract}


called as 'Ghingharoo' (Kala, 2007). P. crenulata is reported to have many traditional and ethnomedicinal uses. It is used in the treatment of hepatic, cardiac, stomach and skin disease (Otsuka et al., 1981; Chauhan, 1999; Khare, 2004). In recent times, different reports on medicinal properties of fruit extract of $P$. crenulata are published. Antiurolithogenic and diuretic activities (Bahuguna et al., 2009), antihypertensive (Negi et al., 2018), anti-inflammatory (Otsuka et al., 1981) and antibacterial (Saklani and Chandra, 2014) properties of fruits extracts have been reported. Moreover, its fruits are considered as potent source of natural antioxidants (Bhatt et al., 2017). Realizing the potential nutraceutical and health benefits of the species, a herbal beverage has been formulated by Defence Institute of Bio-Energy Research (Defence Research \& Development Organisation) from the fruits of $P$. crenulata (Negi et al., 2018). In addition to its edible and medicinal properties, wood (stems and branches) of $P$. crenulata is used for making walking sticks (Polunin and Stainton, 1984; Shah et al., 2006). The species is also used as fodder as its leaves and tender twigs are browsed by goats and sheep. Being a thorny shrub, it is traditionally used as fence around the agricultural fields and orchards by the local people in the hilly areas of the state of Uttarakhand. Moreover, due to its rapid growth and wide adaptability, the species is reported to have potential use for restoration of landslide affected sites in the Himalayan region (Chaudhry et al., 1996). Furthermore, fruits of $P$. crenulata play an important role in food chain in Himalayan forest ecosystems as they are eaten by apes (Shah et al., 2006), as well as by different species of birds (Palita et al., 2011).

Plant phenology is termed as the study of cyclical biological events (flowering, leaf unfolding/bud burst, seed set and dispersal, leaf fall) in relation to climatic conditions (Davi et al., 2011). Importance of phenological studies lies in the fact that they provide knowledge about the patterns of plant growth and development and also on the effects of environmental factors and selective pressure on their flowering and fruiting behavior (Khanduri, 2014). Phenological information of plant species is also very important for development of agronomic practices for their cultivation (Muñoz-Concha and Saud, 2011). Phenological studies are particularly much more important for the non-timber products producing plant species as such types of studies are considered as a fundamental element for their management and exploitation (Salinas-Peba and Parra-Tabla, 2007). Therefore, conduction of phenological studies seems vital for the economically important high-value wild plants, particularly the ones that are yet to be domesticated, not only for understanding their reproductive biology, but also for harnessing their optimum economic potentials.

Realizing the importance of phenological studies, research have been carried out for understanding the influence of phenological patterns on reproductive success of tree species (Omondi et al., 2016). In the Himalayan context, phenological studies have been conducted on trees (Ralhan et al., 1985a; Rawal et al., 1991; Semalty and Sharma, 1996; Sharma and Khanduri, 2007), as well as shrubs (Ralhan et al., 1985b). Nevertheless, information on phenology of most of the ecologically and economically important woody plant species of the Himalaya is scanty. Thus, conduction of phenological studies on a multipurpose shrub species like $P$. crenulata is highly desirable. Therefore, considering the high value (economic and ecological) of $P$. crenulata, as well as the relevance of identifying its phenological events, the present study was carried out. The objectives of the study were to (i) identify and document the phenological features of $P$. crenulata and (ii) to study the patterns of the phenological events of the species under two habitat conditions.

\section{Materials and Methods}

Study site

The study was carried out on the individuals (shrubs) of $P$. crenulata growing in the natural population in Pithoragarh (29 35' N; 80 $13^{\prime} \mathrm{E}$ and $1510 \mathrm{~m}$ a.m.s.l.), Uttarakhand, India, area that falls under the Kumaun region in Western Himalaya province in the Indian Himalayan Region (IHR) (Figure 1). 
Monsoon rhythm determines the basic climatic pattern in the region. There are three main seasons winter (cold and relatively dry) from December to February; summer (warm and dry) from April to mid-June and rainy period (warm and wet) from mid-June to September. In addition, the transitional periods from mid-February to March and October to November can be identified as spring and autumn respectively in the region. The region broadly falls under the lower limit of the moist temperate zone. Two closely located sites, representing two habitat conditions were identified: (i) open pasture (hereinafter OP) and (ii) under canopy (hereinafter UC). Open pasture site represented as a sloped shrubland, where $P$. crenulata plants were growing naturally. Shrub species including Berberis asiatica, Rubus ellipticus and Rosa sp. were also growing along with $P$. crenulata at the OP site. The second site, under canopy, was located nearly $200 \mathrm{~m}$ away from the OP site, where $P$. crenulata plants were growing under the canopy of tree species including Prunus cerasoides, Aesculus indica, Celtis australis and Pyrus pashia. Associated shrub species at UC site included B. asiatica, R. ellipticus and Rosa sp. Major difference in the environment between the two sites was the presence/absence of tree canopy above the individuals of $P$. crenulata. Due to the presence of tree canopy, UC site was shady and therefore, it was presumed as relatively cold and moist in comparison to the OP site (having no canopy cover of trees), which could be considered as relatively hot and dry.

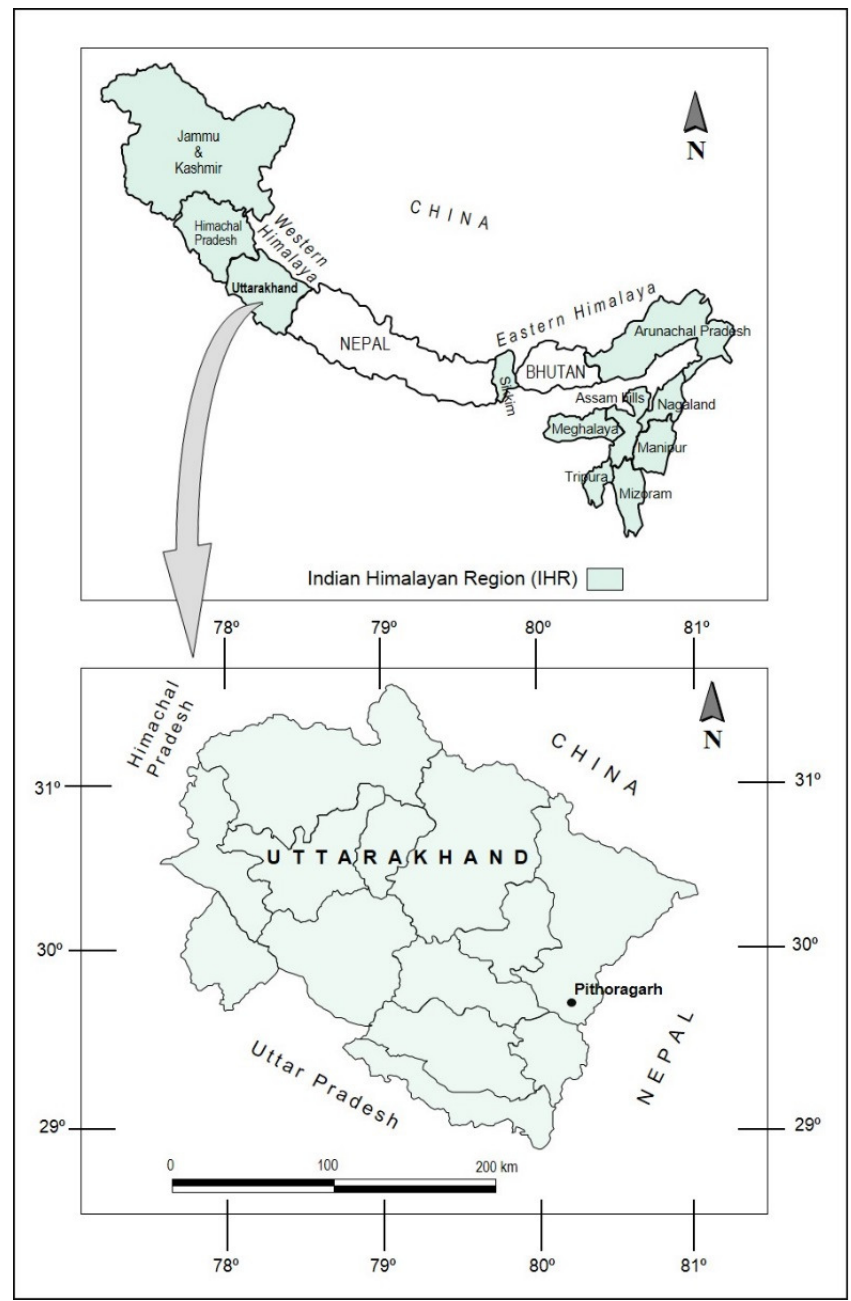

Figure 1. Location of the study area in the Indian Himalayan Region (IHR) 
Sampling

At each site (habitat), a $20 \times 20 \mathrm{~m}$ plot was marked and 5 individuals (shrubs) of P. crenulata, each having canopy diameter of 1.5 to $2 \mathrm{~m}$ were selected for data collection. The selected individuals of $P$. crenulata had 3 to 4 stems, which were 50 to $80 \mathrm{~mm}$ in diameter. On each individual, 5 branches were selected and tagged so that at least one branch could be sampled at lower, middle and top position from the ground level on each plant. In this way, the entire plant could be represented in terms of the position of branches (top, middle and lower) from the ground. On each tagged branch, phenological observations were made on $50 \mathrm{~cm}$ length from its tip. Phenological records on all the tagged branches of the selected individuals of $P$. crenulata were made on five phenological stages - emergence of new leaves and twigs; flowering; fruit setting and development; fruit drop and leaf fall. These observations were recorded during the two successive years i.e. 2017 and 2018, from January to December. Data were recorded at fortnightly interval, i.e., first fortnight (hereinafter FF) and second fortnight (hereinafter SF) of each month during the study period. Data for FF and SF were recorded between $11^{\text {th }}$ and $15^{\text {th }}$ date and $27^{\text {th }}$ and $30^{\text {th }}$ date respectively of each month. However, during the flowering and fruiting stage observation were taken on weekly basis. Data on vegetative growth (leaf and shoot emergence) were recorded on the selected branches of the selected trees by observing and recording the growth stage. Data on total number of flowers per $50 \mathrm{~cm}$ twig length, initial fruit setting (\% of flowers formed fruits), final fruit setting (\% of flowers formed fruits that attained ripening stage), fortnightly fruit growth (diameter) across different months, and rate of fruit drop were collected at the respective phenological stage during both years. Fruit setting (beginning) was considered when the green coloured fruits $(\sim 3 \mathrm{~mm}$ diameter) were visible and having remnant dried petals and stamens remained attached to it. Fruit development was analysed by recording diameter $(\mathrm{mm})$ of 10 randomly selected fruits on each of the 5 tagged branches on all the selected individuals at both sites. Different development stages, as identified by colour of developing fruits, were recorded and photographs were taken.

\section{Statistical analysis}

Independent samples and paired samples $t$-test $($ at $\mathrm{P}<0.05)$ were performed to analyse differences in different parameters between the sites (i.e., OP and UC) and between the years (i.e., 2017 and 2018) respectively. Unless otherwise stated, average values are described as mean \pm standard error. Statistical analysis was performed in Microsoft Office Excel 2013.

\section{Results and Discussion}

Based on the observations recorded in the present study, five phenological events have been identified in P. crenulata (Figure 2):

\section{Emergence of new leaves and twigs}

Emergence of new leaves began in February SF (17 February and 16 February in OP and UC respectively in 2017 and 18 February and 20 February in OP and UC respectively in 2018) when the shiny maroon coloured mixed buds (Figure 3A), appeared on the nodes, as well as on the spur shoots, started opening (bud burst) as the onset of spring flush (Figure 3B). Initially, these buds appeared as maroon-green compact cluster of leaves and subsequently developed into tiny leaves, green in centre and maroon on the edges, by the end of March FF during both years, in both sites. A second vegetative growth period begun during July FF to SF (10 July and 15 July in OP and UC respectively in 2017 and 13 July and 17 July in OP and UC respectively in 2018) during the fruit development phase as new leaves and tender shoots were visible. Emergence of new shoots and leaves remained continued until November SF (Figure 2) in both the sites, during both years. During December and January, the coldest period, vegetative growth did not occur 
34

indicating this as the unfavorable period for new shoot emergence. The emergence of shoots for multiple times in $P$. crenulata indicated that it exhibits multiple flush type of shoot growth. Multiple flushes are reported in several temperate evergreen species though there are other temperate evergreen species that exhibit single (spring) flush only. Temperate evergreen single flush species, however, also have potential of developing shoots in summers (i.e., lammas shoot), which is triggered by the climatic variations or some external factors like herbivory (Nitta and Oshwa, 1997). The pattern of new leaf and shoot emergence were identical in both the sites (i.e., OP and UC) though a difference of a few days was observed between the two years. Similar pattern in bud break of two tree species (Machilus thunbergii and Elaeocarpus japonicus), studied at two closely located, but different kind of sites (i.e., shady understory and exposed ridge) in natural hardwood forest on Fenhuang Mountain (Central Taiwan) were reported by Lu et al. (2012).

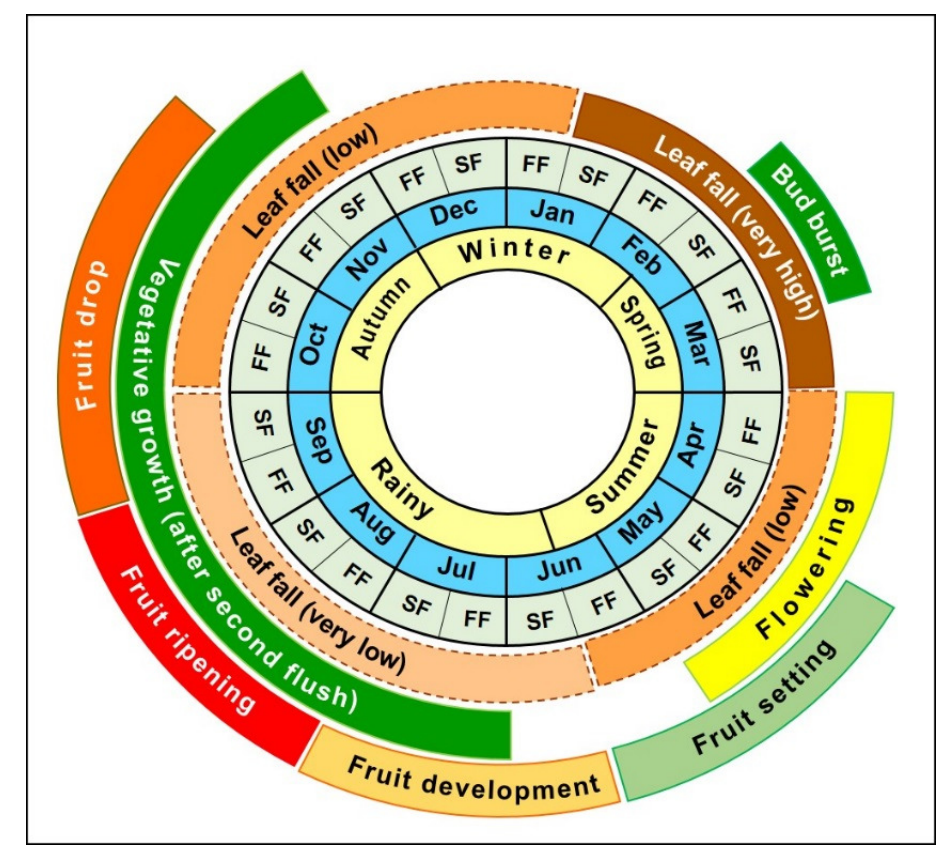

Figure 2. Graphical representation of phenological events in Pyracantha crenulata during different seasons, months and fortnights. FF - first fortnight; SF - second fortnight

\section{Flowering}

Tiny, green coloured and pubescent flower buds were first visible (Figure 3C) during April FF after the expansion of compact maroon green cluster of leaves (Figure 3B) as a result of bursting of mixed buds, mostly on the spur shoots and on the previous year's twigs during 1 April and 3 April in OP and UC respectively in 2017 and 4 April and 7 April in OP and UC respectively in 2018. In spite of the fact that both the sites were located close (nearly $200 \mathrm{~m}$ apart) to each other, flower buds emergence got delayed by 2 and 3 days at UC site in 2017 and 2018 respectively in comparison to OP site. This can be attributed to the shady habitat (microsite) conditions caused by canopy cover of trees species under which plants of $P$. crenulata were growing at the UC site. Sharma and Khanduri (2007) also described similar reasons for variation in floral bud development in Aesculus indica growing under two site conditions in temperate Himalayan region. Moreover, in 2018, flowering was delayed by 3-4 days in comparison to the year 2017. By April FF (i.e., 8 to 12 April) 610 small pinkish green flower buds ( $3 \mathrm{~mm}$ in diameter) attached to a $5-8 \mathrm{~mm}$ long peduncle and arranged in clusters were visible (Figure 3D). During 12-19 April flower buds turned creamy white before opening in both the years, at both the sites (Figure 3E). Flowering initiated on 16 April and 18 April in 2017 and 2018 respectively in OP site whereas in UC site flowering began on 18 and 22 April in 2017 and 2018 respectively 
as the creamy white petals were clearly visible opened (Figure 3F). Flowers were arranged in a compound corymb having 3-5 cm diameter and composed of 6-10 flower and diameter of single flower was 6-9 mm. Peduncle of mature flowers reached up to $10 \mathrm{~mm}$, when flowers were fully opened. Flowering was ended during May SF (19 May in OP and 23 May in UC site in 2017 and 22 may in OP and 25 May in UC in 2018) as there were no unopened flower buds observed on the sampled twigs. Thus, flowering phase completed in 48-50 days in OP and UC sites in both the years.
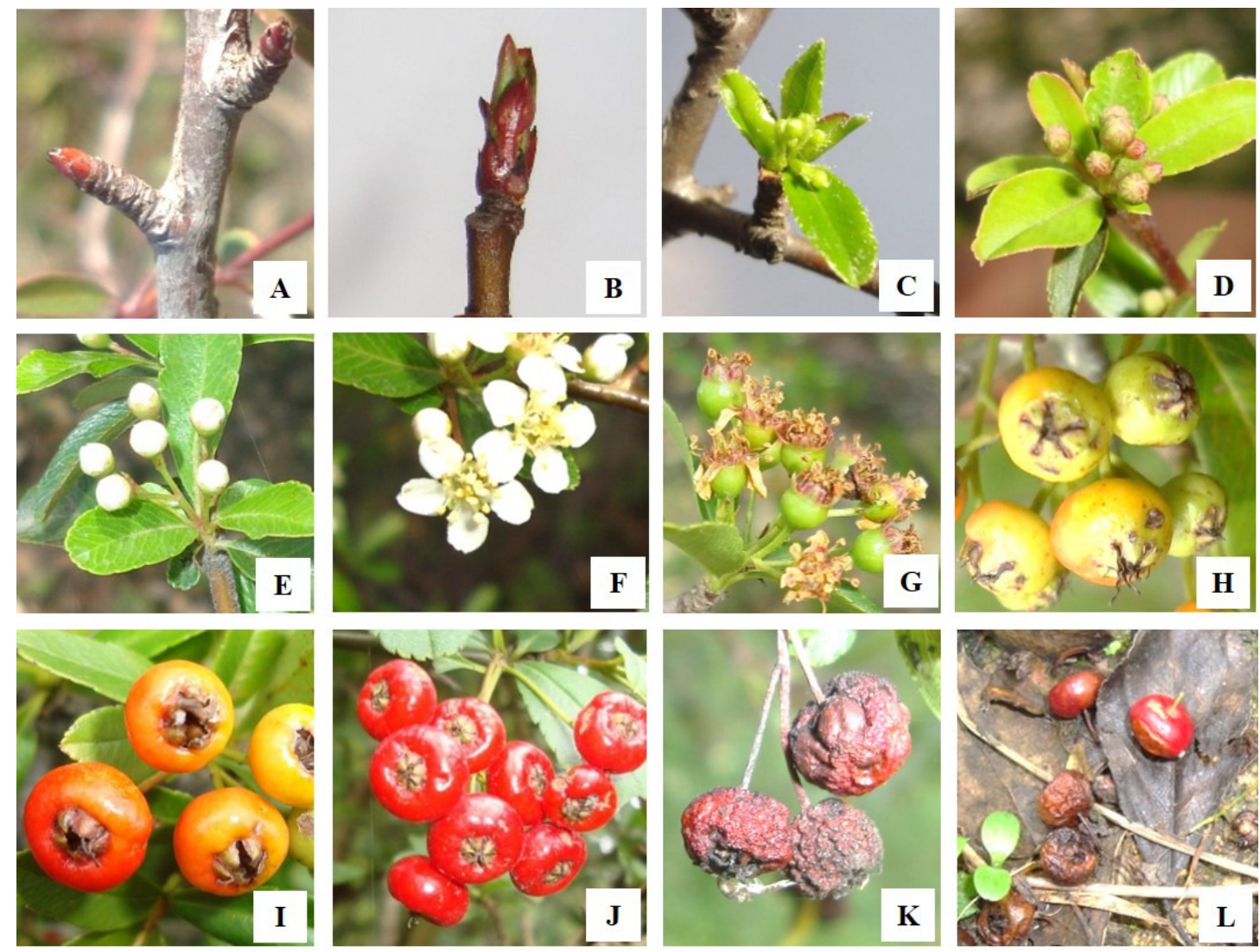

Figure 3. Flowering and fruiting phenological stages of $P$. crenulata: (A) mixed bud, (B) bud burst, (C) emerging flower buds, (D) pinkish green developing flower buds, (E) creamy white flower buds, (F) flowers, $(G)$ fruits with dried petals and stamens attached, $(H)$ pale green fruits, (I) orange-red fruits, $(J)$ deep red (mature) fruits, $(\mathrm{K})$ dried fruits after maturity, $(\mathrm{L})$ dried and mature fruits dropped on ground

\section{Fruit setting and development}

Fruit set started as the tiny green fruits ( $\sim 2 \mathrm{~mm}$ in diameter) having dried petals and stamens attached, were visible (Figure 3G) during the last days of April SF (28 and 30 April in OP and UC respectively in 2017) to early May ( 1 and 4 May in OP and UC respectively in 2018). Initial fruit setting (i.e., \% of flowers formed fruits) was recorded in both the sites, in both the years, after two weeks of completion of flowering. Initial fruit setting did neither differ significantly $(\mathrm{P}<0.05)$ between the sites nor between the years $(65.4 \pm 3.3$ and $71.9 \pm 4.7 \%$ in OP and UC respectively in 2017 and $68.9 \pm 1.8$ and $68.1 \pm 1.8 \%$ in OP and UC respectively in 2018) as reflected in $t$-test analysis (Table 1). In contrast to the findings of the present study, Sharma and Khanduri (2007) reported variation in fruit set of $A$. indica between the sites though the sites in their study were located at different altitudes unlike in the present study. In addition to the initial fruit setting, final fruit setting (i.e., \% of flowers formed fruits that attained ripening stage) was also recorded. Likewise the initial 
fruit setting, final fruit setting also did not differ significantly $(\mathrm{P}<0.05)$ between the sites, as well between the years $(50.4 \pm 3.0$ and $56.7 \pm 4.6 \%$ in OP and UC respectively in 2017 , whereas $55.0 \pm 1.6 \%$ and $54.2 \pm 1.5 \%$ in OP and UC respectively in 2018) (Table 1).

Table 1. Fruit setting (\% of flowers formed fruits) of $P$. crenulata in two sites, over two years of ivestigation

\begin{tabular}{|c|c|c|c|}
\hline Year & Site & \multicolumn{2}{|c|}{ Fruit setting (\% of flowers formed fruits) } \\
\hline & & Initial & At fruit ripening stage \\
\hline 2017 & Open pasture (OP) & $65.4 \pm 3.3$ & $50.4 \pm 3.0$ \\
\hline & Under canopy (UC) & $71.9 \pm 4.7$ & $56.7 \pm 4.6$ \\
\hline 2018 & Open pasture (OP) & $68.9 \pm 1.8$ & $55.0 \pm 1.6$ \\
\hline \multirow{2}{*}{$\mathrm{P}(t$-test) } & Under canopy (UC) & $68.1 \pm 1.8$ & $54.2 \pm 1.5$ \\
\cline { 2 - 4 } & Between sites & $0.10^{n s}$ & $0.10^{n s}$ \\
\cline { 2 - 4 } & Between years & $0.58^{n s}$ \\
\hline
\end{tabular}

${ }^{a}$ independent $t$ - test between the sites (i.e., OP and UC)

${ }^{b}$ paired $t$-test between the years (i.e., 2017 and 2018)

ns - not significant at $\mathrm{P}<0.05$

After the initiation of fruit setting in last days of April SF and early period of May FF (Figure 2), fruit size developed in the subsequent fortnights. In order to assess the fortnightly growth pattern of fruits of $P$. crenulata, fruit diameter and colour were recorded fortnightly in the respective months on a fixed date, i.e., on 15 May (FF), 31 May (SF), 16 June (FF), 30 June (SF), 15 July (FF), 30 July (SF), 17 August (FF) and 31 August (SF) in both the sites, during each year. Almost identical patterns of fruit diameter growth were observed at both the sites during each year as there were no significant differences $(\mathrm{P}<0.05)$ observed $(t$-test analysis) in fruit diameter between the sites, as well as between the years (Figure 4). As such, fruits of $P$. crenulata attained maximum diameter in August SF in both the sites in each year (Figure 4).
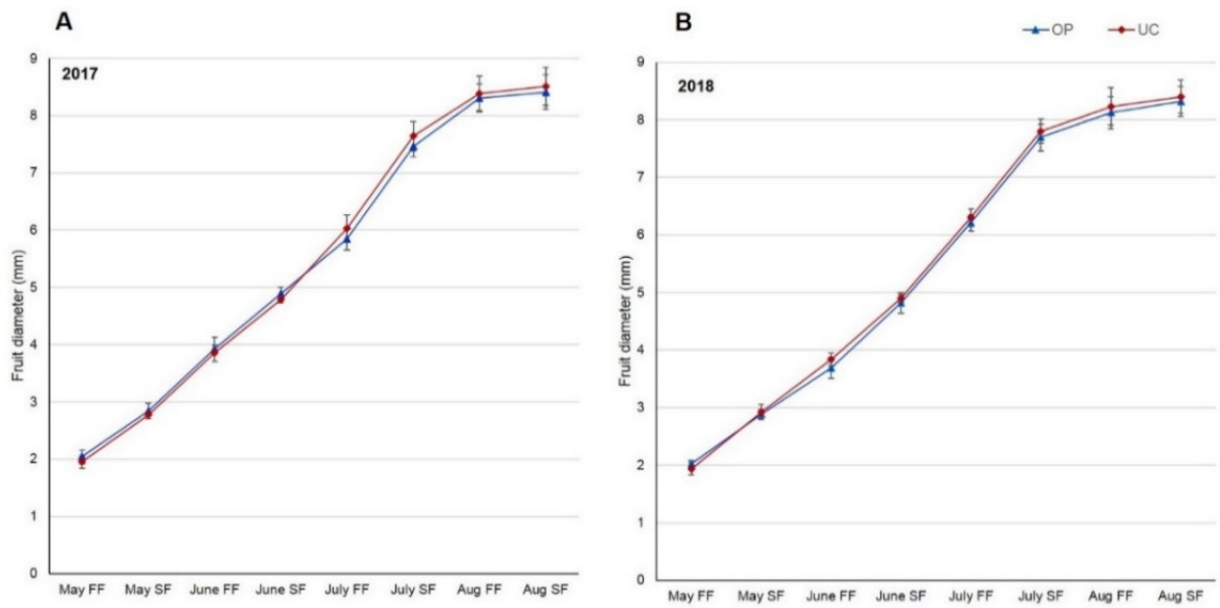

Fruit development period (fortnightly)

Figure 4. Fortnightly fruit diameter growth of $P$. crenulata at two sites (OP and UC) during 2017 (A) and 2018 (B). Independent (between sites) and paired (between years) $t$-test were performed and there were no significant differences $(\mathrm{P}<0.05)$ between the sites, as well as between the years $(\mathrm{OP}-$ open pasture; UC - under canopy; FF - first fortnight; SF - second fortnight). Vertical bars indicate \pm SE 
Up to June SF, fruit colour of $P$. crenulata remained green. However, fruit colour became pale-green during July FF (Figure 3H). Fruit colour further turned to orange-red (Figure 3I) in July SF and finally became deep red (Figure 3J) when they got matured during the last days of August FF. As such, the beginning of fruit ripening (deep red coloured stage) started from 10 and 14 August in OP site during 2017 and 2018 respectively. However, at UC site, there was a delay of few days in initiation of fruit ripening during both the years (14 and 16 August during 2017 and 2018 respectively). Environmental constraints are reported to adversely affect reproductive activity of plant species in their natural habitats (Goldschmidt, 2013). Different microsite conditions (such as shady and moist conditions) caused by canopy cover of trees at UC site, might have contributed in delayed fruit ripening. After the third week of August, 95\% fruits attained maturity as they turned deep red in both the sites during 2017 (21 and 25 August in OP and UC respectively) and 2018 (25 and 28 August OP and UC respectively). Rest of the unripe fruits got mature during early days of September FF. Fruit set (in terms of number of ripened fruits per $50 \mathrm{~cm}$ twig length) of $P$. crenulata did not vary significantly $(\mathrm{P}<0.05)$ between the sites, as well as between the years, as revealed in independent and paired samples $t$-test analysis respectively (Table 2). As such, at OP $74.9 \pm 3.4$ and $78.3 \pm 2.6$ ripened fruits per $50 \mathrm{~cm}$ twig length were recorded in 2017 and 2018 respectively, whereas $76.0 \pm 3.0$ and $74.3 \pm 1.7$ ripened fruits per $50 \mathrm{~cm}$ twig length were formed at UC site during 2017 and 2018 respectively (Table 2).

To summarize, fruiting phase (fruit set to fruit maturity), which took place during the peak summer (May-June) through peak rainy season (July-August), lasted for about four months in $P$. crenulata (Figure 2). To the best of our knowledge, for the first-time comparative patterns of fruiting in $P$. crenulata are described under two site conditions through the present study. As a whole, insignificant difference $($ at $\mathrm{P}<0.05)$ recorded in fruiting, i.e., \% fruit set, fruit size and fruit yield (in terms of number of ripened fruits per $50 \mathrm{~cm}$ twig length) of $P$. crenulata between two closely located, but apparently different (in microsite conditions) sites (OP and UC) exhibit its fitness to two different sites (habitats). Furthermore, based on the findings of the present study, it can be inferred that both the sites (OP and UC) equally nurture fruiting in $P$. crenulata and therefore, its natural populations growing on either of the sites (habitats) in the region could be considered promising for fruit production. Moreover, such natural populations of $P$. crenulata may be prioritised for their conservation and management in order to maintain prolific fruiting not only for promoting its sustainable economic utilization but also as a sustenance for wildlife (frugivores) in the region.

Table 2. Fruit set and drop pattern of $P$. crenulata in two sites during two consecutive years investigated

\begin{tabular}{|c|c|c|c|c|c|c|c|c|}
\hline \multirow[b]{2}{*}{ Year } & \multirow[b]{2}{*}{ Site } & \multirow{2}{*}{$\begin{array}{c}\text { Number } \\
\text { of ripened } \\
\text { fruits per } \\
50 \mathrm{~cm} \text { twig } \\
\text { length }\end{array}$} & \multicolumn{6}{|c|}{$\%$ Fruit drop } \\
\hline & & & Sep. SF & Oct. FF & Oct. SF & Nov. FF & $\begin{array}{c}\text { Nov. } \\
\text { SF }\end{array}$ & $\begin{array}{l}\text { Cumulative } \\
\text { fruit drop } \\
\text { by Nov. SF }\end{array}$ \\
\hline \multirow{2}{*}{2017} & $\begin{array}{c}\text { Open pasture } \\
\text { (OP) }\end{array}$ & $74.9 \pm 3.4$ & $3.9 \pm 0.4$ & $18.2 \pm 0.4$ & $29.3 \pm 1.9$ & $43.5 \pm 2.9$ & $4.7 \pm 0.8$ & $99.6 \pm 0.2$ \\
\hline & $\begin{array}{c}\text { Under canopy } \\
\text { (UC) }\end{array}$ & $76.0 \pm 3.0$ & $3.8 \pm 0.3$ & $16.4 \pm 1.5$ & $28.4 \pm 0.7$ & $41.9 \pm 1.4$ & $8.3 \pm 0.7$ & $98.9 \pm 0.2$ \\
\hline \multirow{2}{*}{2018} & $\begin{array}{c}\text { Open pasture } \\
\text { (OP) }\end{array}$ & $78.3 \pm 2.6$ & $4.0 \pm 0.2$ & $17.5 \pm 0.4$ & $28.8 \pm 1.2$ & $42.3 \pm 1.3$ & $5.7 \pm 1.1$ & $98.3 \pm 0.8$ \\
\hline & $\begin{array}{c}\text { Under canopy } \\
\text { (UC) }\end{array}$ & $74.3 \pm 1.7$ & $3.6 \pm 0.6$ & $18.3 \pm 0.7$ & $28.5 \pm 2.3$ & $40.8 \pm 0.7$ & $6.9 \pm 0.6$ & $98.1 \pm 0.9$ \\
\hline \multirow{2}{*}{$\mathrm{p}(t$-test $)$} & Between sites & $0.31^{n s}$ & $0.19^{n s}$ & $0.37^{n s}$ & $0.40^{n s}$ & $0.10^{n s}$ & $0.04^{*}$ & $0.23^{n s}$ \\
\hline & Between years $b$ & $0.64^{n s}$ & $0.77^{n s}$ & $0.36^{n s}$ & $0.71^{n s}$ & $0.16^{n s}$ & $0.78^{n s}$ & $0.04^{*}$ \\
\hline
\end{tabular}

${ }^{a}$ independent samples $t$ - test between the sites (i.e., OP and UC)

${ }^{b}$ paired samples $t$-test between the years (i.e., 2017 and 2018); ${ }^{*}$ significant at $\mathrm{P}<0.05$; ns - not significant at $\mathrm{p}<0.05$ 


\section{Fruit drop}

Mature fruits remained intact on the plants until September FF as negligible fruit drop (1-2 fruits per $50 \mathrm{~cm}$ twig length) was observed in some of the tagged branches of the selected individuals. However, from September SF onwards, some of the fully ripened fruits started drying and finally dropped on the ground (Figure $3 \mathrm{~K}$ and $\mathrm{L}$ ). Additionally, some of the ripened fruits (deep red coloured) also got dropped even without drying. During September SF, 3.9 \pm 0.4 and $3.8 \pm 0.4 \%$ fruits (of the final number of ripened fruits) dropped at OP and UC respectively in 2017 and $4.0 \pm 0.2$ and $3.6 \pm 0.6 \%$ fruits dropped in OP and UC were recorded in 2018 (Table 2). Substantial increase in fruit drop was observed during October FF onwards in both the sites in both the years and by the end of November SF nearly all the fruits got dropped (Table 2). In order to analyse difference in fortnightly (from September FF to November SF) and cumulative (up to November SF) fruit drop between the sites and between the years, independent samples and paired samples $t$ test respectively were performed. Independent samples $t$-test analysis revealed that fruit drop between the sites did not differ significantly $(\mathrm{P}<0.05)$ during the period except in November SF, when significantly $(\mathrm{P}<0.05)$ higher fortnightly fruit drop was observed in UC in comparison to OP (Table 2). These findings suggest that optimum fruit availability period of the species is up to September SF. After September SF losses in fruit yield may occur due to fruit drop, which will ultimately lead to loss in overall fruit production. Paired $t$-test anlaysis showed that there was no significant difference $(\mathrm{P}<0.05)$ in fortnightly fruit drop (from September FF to November SF) between the years, i.e., 2017 and 2018. Cumulative fruit drop (up to November SF), however, was significantly $(\mathrm{P}<0.05)$ higher in 2017 though the values differed marginally (Table 2).

As such, the findings pertaining to fruiting pattern of $P$. crenulata seems significant as these may be useful for assessing the yield potential of its natural populations and subsequently may help in estimating quantum of availability of its fruits in the region. Moreover, phenological data, particularly that of flowering and fruiting, under two microsite conditions, may also serve as baseline information for future research programmes on standardization of agro-techniques and agronomic requirements for domestication of $P$. crenulata. However, considering the vide altitudinal distribution range $(1,000-2,400 \mathrm{~m}$ a.m.s.l. $)$ of $P$. crenulata (Polunin and Stainton, 1984) and prevalence of immensely diverse agro-climatic conditions in the Himalaya, it would be pertinent to explore and identify other potential habitats of the species across diverse agro-ecological zones under different elevation ranges in the region vis a vis to assess variation in patterns of its phenological attributes. Eventually, such data will be potentially helpful on a larger scale for future studies on domestication of $P$. crenulata in different agro-ecological zones in the Himalaya.

\section{Leaffall}

Evergreen species abscessed their old leaves round the year by which they retain a stable quantity of functional leaves throughout the year (Pao et al., 2016). Likewise, in the present study P. crenulata, an evergreen shrub, was found to shed its leaves throughout the year. Even though magnitude of leaf fall was not measured in the present study, clear variation in intensity of leaf fall was observed among different seasons. Leaf fall intensity in $P$. crenulata was categorized in three broad levels - very high (January SF to March SF), low (April FF to June FF and October FF to January FF) and very low (June SF to September SF) (Figure 2). Very high intensity of leaf fall during January SF to March SF could be inferred by the appearance of some virtually leafless twigs, observed on the selected individuals of $P$. crenulata (Figure 5A). As stated in previous section 'emergence of new leaves and twigs', initiation of spring flush took place in February SF, which falls under the heavy leaf fall period (i.e., January SF to March SF). In this way, leaf abscission (very high intensity) and bud burst in $P$. crenulata occurred in a synchronised manner during the mid-winter through spring. Patterns of leaf fall and spring flush observed in the present study are comparable to those described by Ralhan et al. (1985a, b) for Himalayan evergreen tree and shrub species, in which it is reported that growth of new shoots induces their leaf shedding. This kind of leaf fall pattern was perhaps due to the vernal leaf 
abscission phenomenon, in which the abscission of older leaves is stimulated by the development of new leaves (Addicot, 1978). Just before the bud burst, older leaves turned yellowish due to the depletion of chlorophyll and subsequent visibility of carotenoids and ultimately their abscission took place (Figure 5B and C).
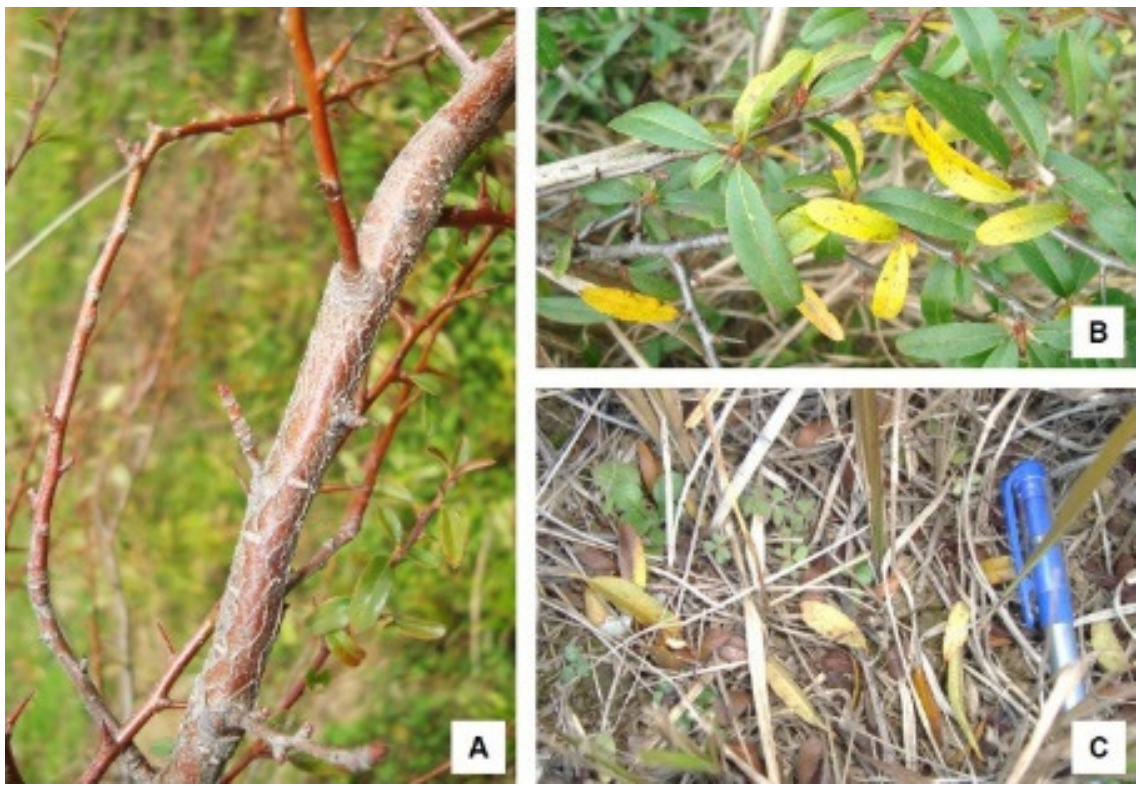

Figure 5. Leaf fall in P. crenulata: (A) leafless twigs observed during March first fortnight, (B) yellow leaves prior to their abscission during February second fortnight, (C) freshly fallen abscised leaves observed under the shrub

\section{Conclusions}

For the first time, identification and documentation of phenological features of $P$. crenulata, an economically promising and ecologically important wild shrub, were carried out through the present research. At large, baseline data on phenological events in P. crenulata under two closely located sites (OP and UC), which differed in microsite conditions, has been generated. In particular, identical patterns of fruiting in $P$. crenulata at both sites investigated has indicated its fitness for fruit production under both environments, i.e., habitat conditions. On this basis, it can be broadly concluded that both kinds of condtions, i.e., open pasture and under canopy, can be considered equally suitable for cultivation of $P$. crenulata for its fruit production.

\section{Acknowledgements}

Defence Research and Development Organisation Headquarters, New Delhi is gratefully acknowledged for sanctioning the project 'Sarhad' (TD/17-18/DIB-78) under which this study was carried out. SKJ wishes to thank Defence Institute of Bio-Energy Research HQ, Haldwani (Uttarakhand) for providing necessary support and facilities for conducting this research. Shri Subir Ranjan, Technical Officer 'A' is thanked for his help during the field studies. 


\section{Conflict of Interests}

The authors declare that there are no conflicts of interest related to this article.

\section{References}

Addicot FT (1978). Abscission strategies in the behavior of tropical trees. In: Tomlinson PB, Zimmermann MH (Eds). Tropical trees as living systems. Cambridge University Press, Cambridge pp 381-398.

Bahuguna YM, Rawat MSM, Juyal V, Gusain K (2009). Evaluation of Pyracantha crenulata Roem for antiurolithogenic activity in albino rats. African Journal of Urology 15(2):159-166.

Bhatt ID, Rawat S, Badhani A, Rawal RS (2017). Nutraceutical potential of selected wild edible fruits of the Indian Himalayan Region. Food Chemistry 215:84-91.

Chaudhry S, Singh SP, Singh JS (1996). Performance of seedlings of various life forms on landslide-damaged forest sites in Central Himalaya. Journal of Applied Ecology 33(1):109-117.

Chauhan NS (1999). Medicinal and aromatic plants of Himachal Pradesh. Indus Publishing Company, New Delhi.

Davi H, Gillmann M, Ibanez T, Cailleret M, Bontemps A, Fady B, Lefevre F (2011). Diversity of leaf unfolding dynamics among tree species: new insights from a study along an altitudinal gradient. Agricultural and Forest Meteorology 151:1504-1513.

Goldschmidt EE (2013). The evolution of fruit tree productivity: A review. Economic Botany 67(1):51-62.

Kala CP (2007). Prioritization of cultivated and wild edibles by local people in the Uttaranchal hills of Indian Himalaya. Indian Journal of Traditional Knowledge 6(1):239-243.

Khanduri VP (2014). Annual variation in floral phenology and pollen production in Lagerstroemia speciosa: an entomophilous tropical tree. Songklanakarin Journal of Science and Technology 36(4):389-396.

Khare CP (2004). Indian herbal remedies: Rational Western therapy, ayurvedic and other traditional usages, botany. Springer Verlag, Berlin Heidelberg.

Lu E-Y, Tsai C-H, Lin J-J, Yang S-H (2012). Leaf emergence, shedding, and lifespan of dominant hardwood species in Chitou, central Taiwan. Botanical Studies 53:255-264.

Muñoz-Concha D, Saud G (2011). Flowering and fruiting phenology of the endangered Chilean tree Gomortega keule. New Zealand Journal of Botany 49(4):497-502.

Negi PS, Singh R, Dwivedi SK (2018). Evaluation of antihypertensive effect of fruit beverage of Crataegus crenulata Roxb. : A wild shrub of Himalayan hills. Defence Life Science Journal 3(2):146-150.

Nitta I, Ohsawa M (1997). Leaf dynamics and shoot phenology of eleven warm-temperate evergreen broad-leaved trees near their northern limit in central Japan. Plant Ecology 130:71-88.

Omondi SF, Odee DW, Ongamo, GO, Kanya JI, Khasa DP (2016). Synchrony in leafing, flowering, and fruiting phenology of Senegalia senegal within Lake Baringo woodland, Kenya: implication for conservation and tree improvement. International Journal of Forestry Research 2016:1-11.

Otsuka H, Fujioka S, Komiya T, Goto M, Hiramatsu Y, Fujimura H (1981). Studies on anti-inflammatory agents. V. A new anti-flammatory constituent of Pyracantha crenulata Roem. Chemical and Pharmaceutical Bulletin 29(11):3099-3104.

Palita SK, Ponkshe AV, Dhar U (2011). Habitat enrichment and its impact on avian diversity: a study at GBPIHED, Kosi-Katarmal, Uttarakhand, India. Current Science 100(11):1681-1689.

Pao NT, Upadhaya K, Mir AH (2016). Phenological behaviour of trees species in subtropical broad leaved humid forests of Jaintia hills in Meghalaya, Northeast India. International Research Journal of Biological Sciences 5(7):10-15.

Polunin O, Stainton A (1984). Flowers of the Himalaya. Oxford University Press, Delhi.

Ralhan PK, Khanna RK, Singh SP, Singh JS (1985). Phenological characteristics of the tree layer of Kumaun Himalayan forests. Vegetatio 60:91-101.

Ralhan PK, Khanna RK, Singh SP, Singh JS (1985). Certain phenological characters of the shrub layer of Kumaun Himalayan forests. Vegetatio 63:113-119.

Rawal RS, Bankoti NS, Samant SS, Pangtey YPS (1991). Phenology of tree layer species from the timber line around Kumaun in Central Himalaya, India. Vegetatio: 93:109-118. 
Saklani S, Chandra S (2014). In vitro antimicrobial activity, nutritional value, antinutritional value and phytochemical screening of Pyracantha crenulata fruit. International Journal of Pharmaceutical Sciences Review and Research 26(1):1-5.

Salinas-Peba L, Parra-Tabla V (2007). Phenology and pollination of Manilkara zapota in forest and homegardens. Forest Ecology Management 248:136-142.

Semalty RK, Sharma CM (1996). Phenology and floral biology of Acer caesium Wall. Indian Forester 122:170-176.

Shah S, Tewari B, Bisht S, Tewari A (2006). Seed maturation indictors in Pyracantha crenulata Roxb. in Kumaun Central Himalaya. New Forests 32:1-7.

Sharma CM, Khanduri VP (2007). Vegetative and reproductive phenophases in Aesculus indica Colebr. at two different altitudes in Himalayan forests. Current Science 92 (2):216-225.

OPEN ACCESS

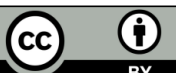

The journal offers free, immediate, and unrestricted access to peer-reviewed research and scholarly work, due SHST supports to increase the visibility, accessibility and reputation of the researchers, regardless of geography and their budgets. Users are allowed to read, download, copy, distribute, print, search, or link to the full texts of the articles, or use them for any other lawful purpose, without asking prior permission from the publisher or the author.

License - Articles published in Notulae Scientia Biologicae are Open-Access, distributed under the terms and conditions of the Creative Commons Attribution (CC BY 4.0) License.

(c) Articles by the authors; SHST, Cluj-Napoca, Romania. The journal allows the author(s) to hold the copyright/to retain publishing rights without restriction. 